
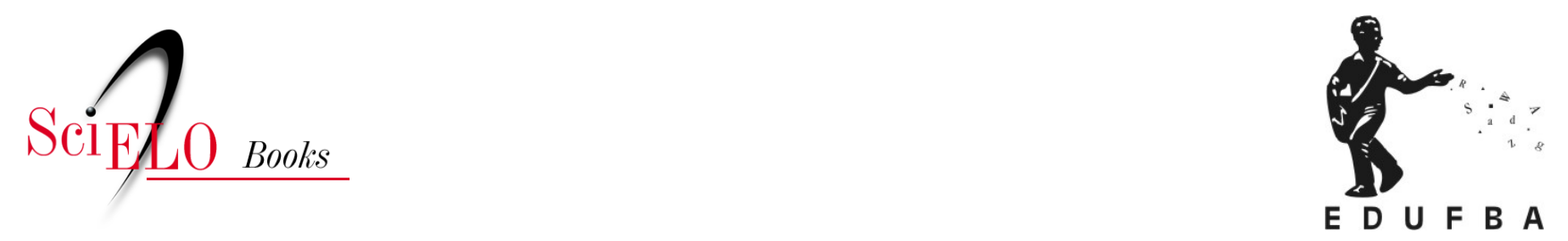

\title{
Problemas, objetos e investigações acerca da judicialização da saúde no Brasil \\ a contribuição do Observatório de Análise Política em Saúde
}

\author{
Luis Eugênio Portela F. de Souza \\ Erik Asley F. Abade \\ Erick Soares Lisboa \\ Izamara Damasceno Catanheide \\ Josele R. Santa Bárbara \\ Kleize Araújo O. Souza
}

\section{SciELO Books / SciELO Livros / SciELO Libros}

SOUZA, L.E.P.F., ABADE, E.A.F., LISBOA, E.S., CATANHEIDE, I.D., BÁRBARA, J.R.S., and SOUZA, K.A.O. Problemas, objetos e investigações acerca da judicialização da saúde no Brasil: a contribuição do Observatório de Análise Política em Saúde. In: TEIXEIRA, C.F., comp. Observatório de análise política em saúde: abordagens, objetos e investigações [online]. Salvador: EDUFBA, 2016, pp. 159-185. ISBN 978-85-232-2021-1. https://doi.org/10.7476/9788523220211.0006.

All the contents of this work, except where otherwise noted, is licensed under a Creative Commons Attribution 4.0 International license.

Todo o conteúdo deste trabalho, exceto quando houver ressalva, é publicado sob a licença Creative Commons Atribição $\underline{4.0}$. 


\section{PROBLEMAS, OBJETOS E INVESTIGAÇÕES ACERCA DA JUDICIALIZAÇÃO DA SAÚDE NO BRASIL a contribuição do Observatório de Análise Política em Saúde}

\section{Introdução}

A Constituição Federal Brasileira de 1988 representou um significativo avanço na democratização do país, incluindo o direito universal à saúde. Na prática, contudo, esse direito não é assegurado plenamente e, com isso, diversas pessoas, de forma individual ou coletiva, têm recorrido aos tribunais para ter garantido seu direito à saúde. Esse novo papel atribuído ao Poder Judiciário significa uma inevitável ampliação de sua atuação, fenômeno que vem sendo chamado de judicialização da saúde. (MACHADO; DAIN, 2012)

A judicialização se refere ao ativismo do Poder Judiciário no âmbito das relações sociais e políticas. Santos e colaboradores (1996) definem a judicialização como fenômeno sócio-histórico, caracterizado pela ampliação da interferência dos tribunais nessas relações, 
dotando o Poder Judiciário de grande protagonismo. Verifica-se assim um alargamento da órbita de atuação do Poder Judiciário sobre espaços que deveriam ser ocupados pelas políticas sociais como, por exemplo, a política de saúde.

As demandas judiciais relacionadas à saúde vêm crescendo exponencialmente no Brasil. É um fenômeno complexo que envolve diversos objetos, incluindo a busca por acesso a internações, a leitos de Unidades de Tratamento Intensivo (UTI), a consultas e exames médicos, a insumos e medicamentos, principalmente. Dessa forma, a intervenção do Poder Judiciário na saúde determina a prestação de serviço ou o fornecimento de medicamentos, almejando à concretização dos direitos fundamentais previstos na Constituição. (DRESCH, 2014)

As ações judiciais, visando a garantir o acesso a bens e serviços de saúde, tiveram grande repercussão no início dos anos 2000, devido ao elevado número de demandas relacionadas aos medicamentos para o tratamento da Síndrome da Imunodeficiência Adquirida (aids), lançados no período. Cerca de 10 anos depois, em 2011, o número de ações relativas à saúde chegou a aproximadamente 240 mil, incluindo demandas de acesso a medicamentos e procedimentos médicos pelo Sistema Único de Saúde (SUS), vagas para internamento em hospitais públicos e ações diversas movidas por clientes de planos e seguros privados de saúde. (SCHEFFER;SALAZAR; GROU, 2005; CONSELHO NACIONAL DE JUSTIÇA, 2011)

Nesse sentido, o estudo da judicialização da saúde é de grande relevância para a Saúde Coletiva, pois ajuda a entender as dificuldades relacionadas à gestão e à organização dos sistemas e dos serviços de saúde para assegurar o acesso da população a bens e serviços de ordem sanitária. É também relevante por permitir identificar os impactos das decisões judiciais na formulação e implantação de políticas de saúde, assim como na estruturação, no financiamento e no planejamento dos serviços e sistemas de saúde.

Além disso, o estudo das causas do fenômeno pode levar à compreensão das diversas relações existentes entre os interessados nos 
processos de demandas judiciais em saúde, dentre eles os usuários dos serviços e as organizações nãogovernamentais, os gestores e os profissionais de saúde, os operadores do direito, o setor produtivo, entre outros, que representam elementos de pressão da sociedade sobre os sistemas públicos e privados de saúde para o uso e a incorporação de tecnologias em saúde.

Vale ressaltar, ainda no âmbito da Saúde Coletiva, que a judicialização da saúde leva a um debate sobre o direito individual versus o direito coletivo, na medida em que muitas das ações individuais envolvem tecnologias de alto custo, com impacto orçamentário significativo e, portanto, levantam a questão de até que ponto essas ações são justas, já que vão reduzir os recursos que seriam empregados em outros problemas de saúde da população, que podem atingir parcelas significativas da população.

A saúde é um bem comum, um direito social, a ser garantido de forma equitativa. Como os recursos são finitos, os gestores têm a responsabilidade de definir prioridades, respeitando, entre outros, o princípio da igualdade. Nesse sentido, sempre que uma sentença judicial impõe a oferta de um tratamento de alto custo, não previsto nas prioridades, a uma única pessoa coloca-se a questão sobre a equidade, dado que o custeio desse tratamento pode significar a falta de recursos para o cuidado a muitas outras pessoas. (BORGES; UGÁ, 2009; D’ESPINDULA, 2013)

A rigor, a decisão jurídica relativa ao caso individual daquela pessoa que recorreu ao Judiciário não deveria desconsiderar a política pública destinada a garantir o mesmo direito a toda a coletividade, sob pena de privilegiar o interesse de um em detrimento ao de outros. (MARQUES; DALLARI, 2007)

Assim, a judicialização da saúde é um problema de pesquisa. É um fenômeno complexo, de múltiplos determinantes, que envolve dilemas e questões de ordem ética, legal, política e econômica. $\mathrm{E}$, apesar de diversos pesquisadores virem se debruçando sobre o tema e produzindo importantes trabalhos ao longo dos últimos 10 anos (BORGES; UGÁ, 2010; CHIEFFI; BARATA, 2009, 2010; 
DINIZ; MEDEIROS; SCHWARTZ, 2012; LOPES et al., 2010; MESSEDER; OSORIO-DE-CASTRO; LUIZA, 2005; SANTOS; TERRAZAS, 2014; TORRES, 2013;VIEIRA, 2008), há ainda lacunas no conhecimento a serem exploradas. Continua relevante, portanto, identificar problemas, construir objetos e conduzir investigações acerca do fenômeno da judicialização da saúde.

\section{Problemas e objetos de investigação acerca da judicialização da saúde}

Dado que as decisões judiciais relativas às questões sanitárias têm influenciado os processos de formulação e implantação das políticas de saúde, é imperativo estudar essas decisões, sejam as de primeiras instâncias, sejam as de instâncias recursais, através da análise de seus aspectos políticos, sociais, éticos, jurídicos, médicos e sanitários, no intuito de compreender o fenômeno e de trazer elementos para o aprimoramento das políticas de saúde em curso.

Em vista disso, o grupo responsável pelo acompanhamento das decisões judiciais relativas à saúde do Observatório de Análise Política em Saúde (OAPS) do Instituto de Saúde Coletiva da Universidade Federal da Bahia (ISC/UFBA) direciona seu olhar, desde a perspectiva da saúde coletiva, para o fenômeno da judicialização da saúde no Brasil, buscando compreender a sua dinâmica, as suas causas e os seus efeitos em suas relações com os sistemas de saúde público e privado.

Desde 2012, esse grupo vem realizando investigações científicas para analisar essas decisões judiciais relativas à saúde. Tem definido problemas e objetos de estudos que se projetam no espaço das relações sociais que envolvem o fenômeno e revelam as suas múltiplas facetas - ideológicas, éticas, econômicas, políticas e sociais - a partir dos pontos de vista de distintos sujeitos que atuam nos campos da saúde e do direito. Nessa direção, tem procurado realizar investigações cujos objetos possam apreender o fenômeno da judicialização à saúde na sua complexidade e nas suas diversas dimensões. 
Os problemas e os objetos de que tratam esses estudos dizem respeito, especificamente: à questão da judicialização de medicamentos no Brasil (como caracterizá-la?); ao acesso ao tratamento da diabetes na Bahia (por que se recorre ao judiciário para obter acesso a esse tratamento?); à judicialização da assistência médica suplementar em Pernambuco (são distintas suas características em relação aos estados do centro-sul do país?); à influência da judicialização na incorporação de biomedicamentos ao SUS (as sentenças judiciais têm influenciado ou não as decisões acerca da incorporação de biotecnologias ao SUS?); e ao panorama da judicialização da saúde no estado da Bahia (qual a dimensão e as características do fenômeno no estado?).

Os distintos objetos escolhidos para estudo buscam descrever e analisar, de maneira articulada, as diversas dimensões da judicialização da saúde, de modo que não se constituem em investigações isoladas, mas conformam um único programa de pesquisa que representa um esforço para a apreensão da complexidade do fenômeno. Desse modo, adotou-se a opção de apresentar detalhadamente, neste capítulo, os cinco estudos desenvolvidos pela equipe de pesquisadores do eixo de acompanhamento das decisões judiciais em saúde, sendo três deles já concluídos e dois em andamento.

Apesar de ter adquirido relevância social e política recentemente, a judicialização já motivou a realização de uma grande quantidade de estudos com variadas abordagens. (BORGES; UGÁ, 2010; CHIEFFI; BARATA, 2009, 2010; DINIZ; MEDEIROS; SCHWARTZ, 2012; LOPES et al., 2010; MESSEDER, 2005; SANTOS; TERRAZAS, 2014; TORRES, 2013; VIEIRA, 2008)

No caso do acesso a medicamentos, já foram realizados muitos estudos que descrevem ou caracterizam a situação fática da judicialização no Brasil. Nesse sentido, foi oportuno produzir uma síntese do que já se conhece sobre o tema. Com esse propósito, foi desenvolvido o primeiro estudo do grupo que traçou o perfil da produção acadêmica sobre esse tema, através da análise dos estudos publicados de 1988 a 2011 e da descrição das características das ações judiciais quanto 
aos elementos processuais, médico-sanitários e político-administrativos e as características sociodemográficas dos autores dos processos.

Conhecido o perfil da produção acadêmica sobre a judicialização de medicamentos no Brasil, o segundo estudo tomou como objeto as ações judiciais impetradas contra a Secretaria da Saúde do Estado da Bahia (Sesab), para se obter o acesso ao tratamento da diabetes, em especial, os argumentos ou as motivações dos autores das ações e do réu, no período de 2010 a2013. A escolha da diabetes como patologia específica para estudo se justificou por ser uma doença crônica de alta prevalência na Bahia e no Brasil. Segundo dados da Sesab, em 2009 cerca de 6,5\% da população baiana, aproximadamente 636 mil pessoas, sofrem com a diabetes. (BAHIA, 2012) Além disso, Torres (2010) demonstra que, entre 2002 e 2008, houve uma grande quantidade de ações judiciais para o fornecimento de medicamentos para o tratamento da diabetes, sendo que, dos quatro medicamentos mais solicitados, nesse período, dois são para o tratamento dessa patologia.

164 Com o propósito de analisar a judicialização da saúde no sistema privado, foi desenvolvido um terceiro estudo, sob forma de dissertação de mestrado, que tomou como objeto as decisões judiciais relativas à assistência médica suplementar. Os poucos trabalhos que se debruçam sobre esse tema foram realizados na região Sudeste, notadamente em São Paulo e Rio de Janeiro.

Em vista disso, a pesquisa conduzida pelo OAPS voltou seu foco para a região Nordeste, analisando as ações judiciais contra operadoras de planos e seguros de saúde em Pernambuco. Procurou, assim, contribuir para preencher a lacuna de conhecimento sobre a judicialização fora do eixo Rio-São Paulo, além de avançar na discussão de questões centrais para o campo da saúde coletiva como a segmentação do sistema, a regulação do mercado, a incorporação tecnológica e as relações entre atores políticos como os tribunais e os operadores do direito, as empresas de planos e seguros, os profissionais de saúde e a sociedade civil. 
O estudo em questão se apresentou sob a forma de dois artigos. Enquanto o primeiro artigo descreveu as características gerais das ações judiciais, o segundo analisou a fundamentação jurídica e argumentativa das sentenças judiciais, buscando identificar os marcos regulatórios e legais da saúde suplementar utilizados pelos tribunais.

Além das três pesquisas já concluídas, estão sendo desenvolvidas duas teses de doutorado que buscam compreender outras dimensões do fenômeno da judicialização da saúde.

Um desses estudos, intitulado As decisões judiciais e a incorporação de medicamentos biológicos ao SUS, toma como objeto a influência das sentenças judiciais no processo de decisão relativo à incorporação de biomedicamentos ao SUS, no período de 2010 a 2015.

O interesse pela temática decorre do fato de que o recurso do cidadão ao Poder Judiciário para ter garantido o que entende ser um direito seu está impulsionando, na prática, a compra e o fornecimento de medicamentos essenciais ou de alto custo por parte do MS e das secretarias estaduais e municipais de saúde e, portanto, pode estartambém influenciando o processo de incorporação de tecnologias pelo SUS.

Ressalta-se que os gastos do SUS com medicamentos biotecnológicos são significativos e têm aumentado nos últimos anos. Conforme dados do MS, trazidos por Reis, Pieroni e Souza (2010) o total de gastos do SUS com medicamentos de alto custo no ano de 2008 foi de R\$ 2,3 bilhões (contra R 513 milhões em 2003). Foram 220 medicamentos destinados ao tratamento de 76 doenças que afetaram aproximadamente 730 mil usuários. Deste total, 41\% foram gastos com medicamentos biológicos. Em termos de volume, no entanto, os biológicos respondem por apenas $2 \%$ do total de medicamentos adquiridos, revelando um grupo de altíssimo valor agregado. (REIS; PIERONI; SOUZA, 2010) Em 2013, os biomedicamentos representaram 5\% dos medicamentos disponibilizados pelo SUS, seus custos, contudo, representaram $43 \%$ dos gastos totais do MS com medicamentos. O orçamento do MS para a compra de medicamentos cresceu 78\% entre os anos de 2010 e 2014. Em 2010, 
foram investidos R \$ 6,9 bilhões e em 2014 o orçamento previsto foi de R\$ 12,4 bilhões. (BRASIL, 2013, 2014)

Nessa perspectiva, pode-se afirmar que o aumento dos gastos púbicos com medicamentos pode estar associado, dentre outras causas, à incorporação de novas tecnologias ao SUS, que, por sua vez, pode estar relacionada às decisões judiciais que obrigam o fornecimento de medicamentos pela União, pelo estado ou pelo município. (CHIEFFI; BARATA, 2009, 2010; LOPES, 2010; VIEIRA, 2008; VIEIRA; ZUCCHI, 2009)

Apesar de terem sido realizados, ao longo dos últimos anos, diversos estudos para avaliar os efeitos da judicialização sobre as políticas de saúde, ainda não se conhecem seus efeitos específicos sobre o processo de incorporação de medicamentos biotecnológicos.

O outro estudo em desenvolvimento - uma tese de doutorado - trata das decisões judiciais no âmbito da Sesab. Toma como objeto de investigação a evolução da judicialização no âmbito da Sesab, desde a primeira demanda judicial contra o estado até a última demanda de 2016, tendo como objetivos específicos:

a. caracterizar as ações judiciais quanto aos seus elementos médico-sanitários e político-administrativos e;

b. discutir a relação entre as políticas de saúde do estado da Bahia e as demandas judiciais no decorrer do tempo analisado.

A originalidade dessa pesquisa se atém ao fato de buscar delinear um panorama da judicialização, abarcando todos os objetos das ações judiciais, sejam bens (medicamentos, próteses, insumos etc.), sejam serviços (internações, exames, homecare etc.). Visa assim produzir conhecimentos que ajudem a compreender a diversidade concreta do fenômeno da judicialização e possam subsidiar o processo de formulação e implantação de políticas de saúde. 


\section{Abordagens metodológicas dos estudos sobre a judicialização}

Para abordar os problemas e os objetos de investigação acima apresentados, os estudos do OAPS adotaram ou adotam estratégias metodológicas diferenciadas, incluindo abordagens quantitativas e qualitativas. As técnicas de coleta e produção de dados incluem: busca dos processos judiciais nos sítios eletrônicos dos tribunais de justiça, entrevistas com informantes-chaves, observação sistemática e pesquisa documental. As estratégias de análise envolvem análise de conteúdo, triangulação de dados, além da análise dos dados quantitativos através do programa STATA versão 12 .

Nesse ponto, vale destacar que tem sido enriquecedor aliar a consulta às sentenças em segunda instância, disponíveis na internet, com a consulta direta aos processos judiciais disponibilizados, no caso, pela Sesab. Entre outras coisas, as primeiras fornecem informações objetivas sobre o fundamento legal das decisões e os aspectos processuais das ações, enquanto os processos iniciais fornecem um conjunto amplo de informações que favorecem a caracterização dos autores e dos aspectos médico-sanitários e político-administrativos. Além disso, junto com as entrevistas e os registro das observações, essa aliança aumenta a força da triangulação de dados.

A primeira pesquisa realizada no âmbito do OAPS - Judicialização de medicamentos no Brasil: uma revisão sistemática (TORRES, 2013) - adotou um método de revisão sistemática estruturado em seis etapas:

a. formulação do problema, através de uma pergunta de investigação;

b. pesquisa na literatura -identificação das fontes (base de dados) a serem consultadas, definição de palavras-chaves, estratégia de busca, estabelecimento de critérios de inclusão e exclusão;

c. avaliação da qualidade;

d. análise dos dados; 
e. interpretação dos resultados; e

f. apresentação das conclusões. (COOPER; HEDGES, 2009)

Utilizaram-se como fontes de informação as bases Literatura Latino-Americana e do Caribe em Ciências da Saúde (Lilacs), Scientific Electronic Library Online (Scielo), Medical Literature Analysis and Retrieval System Online (Medline), o banco de teses e dissertações da Coordenação de Aperfeiçoamento de Pessoal de Nível Superior/Conselho Nacional de Desenvolvimento Científico e Tecnológico (Capes/CNPq), o Google Acadêmico, além das referências dos estudos selecionados.

Fruto dessa pesquisa, elaboraram-se dois artigos.

O primeiro artigo relaciona certas características dos estudos revisados: o ano de publicação, a filiação institucional do autor principal, a localização regional da instituição, o tipo de publicação (artigo, dissertação, tese ou capítulo de livro), as palavras-chave utilizadas e a área do saber. A seguir, descreve a natureza das pesquisas, os objetivos de investigação e as características gerais das ações judiciais avaliadas.

$\mathrm{O}$ segundo artigo analisa os trabalhos de natureza empírica que permitem caracterizar detalhadamente as ações judiciais e os seus autores. Com base no Manual Indicadores de Avaliação e Monitoramento das Demandas Judiciais de Medicamentos (PEPE, 2011), foram identificadas nos trabalhos selecionados as características das ações judiciais quanto aos elementos processuais, médico-sanitários e político -administrativos e as características sociodemográficas dos autores dos processos.

Outro estudo realizado no âmbito do OAPS se intitulou Acesso ao tratamento da diabetes na Bahia: por que se recorre ao Judiciário? (LISBOA, 2015) e teve por objetivo analisar as ações judiciais impetradas contra a Sesab, para se obter o acesso ao tratamento da diabetes. Em especial, buscou identificar as motivações do autor da ação e os argumentos do réu.

Tratou-se de um estudo documental retrospectivo (TOBAR; YALOUR, 2001), cuja unidade de análise foi à ação judicial movida 
contra a Sesab para o fornecimento de medicamentos para o tratamento da diabetes no período compreendido entre os anos de 2010 e 2013. Foram identificadas 325 ações judiciais e, ao final, selecionadas para análise 154 ações. A análise foi dividida em duas etapas: a primeira contemplou as características das ações judiciais e a segunda os motivos ou os argumentos do autor que recorreu à via judicial, assim como os do réu.

Na primeira etapa, as categorias tiveram como referência quatro dimensões: características sociodemográficas dos autores e características processuais, médico-sanitárias e político-administrativas das ações. (PEPE, 2011) Na segunda etapa, as motivações ou os argumentos do autor da ação foram classificados em quatro categorias:

a. necessidade do uso da insulina análoga,

b. hipossuficiência financeira,

c. dever do estado em fornecer o medicamento,

d. questões burocráticas que dificultam o acesso.

Os argumentos do réu, por sua vez, foram ordenados em duas categorias:

a. desobrigação do fornecimento de medicamentos não padronizados pelo SUS e

b. (inexistência de evidências científicas da superioridade terapêutica das insulinas análogas em relação às disponíveis pelo SUS, NPH e a Regular.

O estudo intitulado $A$ judicialização da assistência médica suplementar: um estudo de caso em Pernambuco (ABADE, 2015) apresenta como primeiro artigo uma descrição das características gerais das ações judiciais, cumprindo a função de caracterizar a judicialização da saúde suplementar em um estado do Nordeste. O segundo artigo representa um esforço de apreender e compreender a fundamentação jurídica e argumentativa das decisões judiciais, buscando identificar o marco regulatório da saúde suplementar acionado pelos tribunais. 
Trata-se de uma pesquisa que analisa todas as ações judiciais do tipo Agravo de Instrumento que diziam respeito à assistência médica suplementar, julgadas em segunda instância no Tribunal de Justiça de Pernambuco (TJPE) no biênio 2012-2013. A busca foi realizada no sítio eletrônico do tribunal, com os descritores: plano de saúde, seguro-saúde e saúde suplementar. Os critérios de exclusão foram: ações repetidas e que tratavam bens ou serviços odontológicos.

Para a coleta de dados, foi utilizado um roteiro semiestruturado, dividido em três dimensões:

a. características da ação judicial: identificação dos acórdãos, data do julgamento, titularidade do autor da ação, tema da ação, modalidade da operadora, nome da operadora, forma e data de contratação do plano/seguro, resultado do processo;

b. base legal: leis, súmulas ou jurisprudências utilizadas; e

c. aspectos regulatórios: normas da Agência Nacional de Saúde Suplementar (ANS), normas anteriores à criação da ANS publicadas por outros órgãos, pareceres ou outras publicações de associações e entidades.

A análise dos dados foi realizada em duas etapas. Na etapa quantitativa, utilizou-se o programa STATA versão 12 para o cálculo de frequências absolutas e relativas. Para a análise da distribuição dos tipos de operadoras nas ações judiciais, foi calculado o indicador de litigância, dividindo a população litigante pela população total de clientes de cada modalidade contabilizada pela ANS no período. Na etapa qualitativa, empregou-se a análise de conteúdo. (BARDIN, 1977)

Em relação às investigações em desenvolvimento, o estudo $A s$ decisões judiciais e a incorporação de medicamentos biológicos ao Sistema Único de Saúde, de abordagem qualitativa, encontra-se em fase de produção de dados através da realização de entrevistas semiestruturadas com os membros da Comissão Nacional de Incorporação de Tecnologias em Saúde (Conitec), de pesquisa documental e da observação sistemática. A triangulação de dados entre essas técnicas será utilizada para reforçar a confiabilidade dos achados. Essas técni- 
cas de pesquisa servirão tanto para produzir dados que permitam a descrição geral do processo de trabalho da Conitec, quanto para a realização de um estudo de caso referido ao traztuzumabe (Herceptin), primeiro biomedicamento incorporado ao SUS após decisão favorável da Conitec, através das portarias n. ${ }^{\circ}$ 18/2012 e n. ${ }^{\circ}$ 19/2012 da Secretaria de Ciência, Tecnologia e Insumos Estratégicas. A análise das entrevistas, dos documentos e dos registros da observação será feita por meio da análise de texto. (RYAN; BERNARD, 2000)

$\mathrm{O}$ segundo estudo em desenvolvimento, sobre as decisões judiciais no âmbito da Sesab, também de abordagem qualitativa, tomará como base para a produção de dados o Manual de Indicadores de Avaliação e Monitoramento das Demandas Judiciais de Medicamentos. (PEPE , 2011) Assim, por meio de pesquisa documental, será realizada a caracterização das ações judiciais, quanto aos elementos médico-sanitários e político-administrativos no âmbito da Sesab, após acesso aos processos judiciais existentes nessa secretaria. Além disso, informantes-chaves serão entrevistados, com o intuito de se obter informações acerca da relação entre as políticas de saúde do estado e as ações judiciais transitadas no decorrer do tempo analisado.

\section{Principais resultados}

$\mathrm{O}$ artigo "Produção acadêmica sobre as demandas judiciais de medicamentos no Brasil: uma revisão sistemática” (TORRES, 2013) analisou 86 estudos, observando uma publicação contínua de trabalhos desde 2003, quando foi divulgada a primeira pesquisa sobre o tema.

Dentre os principais achados do estudo, verificou-se que o assunto tem sido bastante explorado por autores vinculados a instituições de váriasregiões do país, com destaque para o Sudeste. A Escola Nacional de Saúde Pública (ENSP), situado no Rio de Janeiro, é a instituição com o maior número de publicações, alcançando $13 \%$ do total de estudos analisados. Outras cinco instituições publicaram, 
cada uma, cinco estudos: MS, Universidade de São Paulo (USP), Universidade Federal de Minas Gerais (UFMG), Universidade Federal de Santa Catarina (UFSC) e Universidade de Brasília (UnB).

No que se refere aos tipos de documento, os artigos representam mais de 50\% das publicações, o que indica que o tema, apesar de recente, já está incorporado à agenda científica. Evidencia-se ainda que a saúde é a área que mais tem abordado o tema, especialmente a Saúde Coletiva, o que pode estar relacionado aos impactos da judicialização no funcionamento do sistema de saúde como um todo. Esses estudos têm destacado, especialmente, as características médico-sanitárias e político-administrativas das demandas judiciais, considerando a eficácia, a efetividade e a segurança dos produtos ofertados e a competência administrativa e econômica da administração pública na organização da assistência farmacêutica.

Quanto aos objetivos de investigação, os estudos evidenciam o amplo escopo do debate sobre a judicialização do acesso a medicamentos. Abordam, dentre outros temas: o acesso a medicamentos que integram as listas do SUS e a existência de alternativas terapêuticas para aqueles que não constam nos elencos; a análise dos argumentos dos atores envolvidos nos processos; a interferência dessas demandas nas políticas públicas e as estratégias para o enfrentamento da judicialização da saúde.

No que diz respeito ao segundo artigo, "Caracterização da judicialização do acesso a medicamentos no Brasil: uma revisão sistemática”, fruto da mesma pesquisa, a análise dos 37 estudos empíricos selecionados permite identificar os aspectos já conhecidos do fenômeno, assim como os pontos pouco esclarecidos e as lacunas do conhecimento.

Em primeiro lugar, alguns fatos já estão bem estabelecidos pelas pesquisas. A prescrição médica é o documento fundamental - necessário e suficiente - para o deferimento do pedido liminar pelo juiz. Quase todos os pedidos são acolhidos com a antecipação da tutela, sem qualquer outra exigência judicial. Ademais, a decisão inicial é, quase sempre, mantida quando da sentença ou do acórdão. 
Os estados são os réus mais frequentes nos processos. Prevalecem os pedidos individuais sobre os coletivos e predomina a prescrição pelo nome comercial, em detrimento da denominação genérica. Parcela considerável das ações poderia ter sido evitada, caso fossem observadas as alternativas terapêuticas presentes nas listas do SUS. Os medicamentos sem registro na agência reguladora e com indicação de uso off label constituem exceções nas demandas judiciais.

Em segundo lugar, há diversos pontos ainda não esclarecidos perfeitamente. Pelo número reduzido de estudos que analisam as características sociodemográficas, não se pode caracterizar o autor das demandas judiciais. Há indícios de que a judicialização esteja favorecendo indivíduos com boas condições socioeconômicas, mas são necessários estudos mais abrangentes para traçar o perfil do demandante no país como um todo. De modo similar, não se pode afirmar que os valores gastos com a compra de medicamentos demandados judicialmente comprometam o orçamento do SUS. Também não se sabe ao certo qual o percentual de pacientes que recorreram ao Judiciário, depois de terem feito demandas por via administrativa. Tampouco se sabe se os medicamentos que pertencem aos componentes da Política de Assistência Farmacêutica foram demandados judicialmente por falhas na gestão ou porque constavam da mesma prescrição de um medicamento nãopertencente que teria motivada a demanda ou ainda por outra razão.

Em terceiro lugar, a análise dos estudos permitiu a identificação de lacunas no conhecimento sobre a judicialização do acesso a medicamentos, em especial: quais os desfechos da utilização do medicamento demandado judicialmente; se é o desabastecimento que tem gerado os pedidos judiciais; qual o nível de conhecimento pelos prescritores das listas do SUS e o seu grau de adesão às mesmas.

O estudo intitulado Acesso ao tratamento da diabetes na Bahia: por que se recorre ao Judiciário? (LISBOA, 2015) constatou que, dentre as ações judiciais, houve o predomínio de requisições de análogos de insulina. A demanda foi crescente até o ano de 2012, ocorrendo 
uma queda nas ações em 2013 que decorreu, certamente, da incorporação desses medicamentos pelo estado.

Constatou também que a maioria dos autores é do sexo feminino, a faixa etária maior que 60 anos é predominante e os autores das ações recebiam de até um salário mínimo. Eram, na sua maioria aposentados $(39 ; 24,7 \%)$, salientando que $51(32,3 \%)$ autores não tiveram a ocupação informada. A maioria residia na capital Salvador (65 autores; 41,1\%). (LISBOA, 2015) Essa caracterização sociodemográfica mostra que prevalecem setores sociais desfavorecidos economicamente e pessoas situadas na faixa etária de maior prevalência da diabetes. Isso sugere que, nesse caso, indivíduos com condições socioeconômicas limitadas tiveram acesso à Justiça, diferentemente do que encontraram outros estudos acerca da judicialização. A maior demanda por autores residentes na capital e em cidades do interior de grande porte demonstra que estes têm maior acesso aos serviços jurídicos e de saúde.

Quanto aos aspectos processuais, o estudo evidenciou a fre174 quente atuação da Defensoria Pública do Estado. Curiosamente, contudo, prevalece a prescrição emitida por médicos não vinculados ao SUS, o que indica que mesmo pessoas desfavorecidas economicamente recorrem aos médicos particulares. Na hora de comprar o medicamento prescrito, no entanto, essas pessoas, não dispondo de recursos, buscam o Judiciário. Dentre as motivações dos autores, destacam-se a hipossuficiência financeira, a necessidade do tratamento não disponível pelo SUS, o direito à saúde e as dificuldades de acesso. A defesa do réu se concentra nas estratégias de eximir-se da responsabilidade do fornecimento de medicamentos não padronizados pelo SUS e de afirmar que não há evidências científicas da superioridade terapêutica das insulinas análogas em relação às disponíveis pelo SUS (NPH e regular).

$\mathrm{O}$ fato, constatado nesse estudo, dos juízes estarem deferindo solicitações de medicamentos que não constam das listas do SUS ou são prescritos pelo nome comercial revela o desconhecimento por parte do Judiciário das políticas de medicamentos e de assistência 
farmacêutica e, em particular, das normas sanitárias que orientam o uso racional dos medicamentos, incluindo a recomendação do uso do nome genérico pelas prescrições do SUS, o que pode, no limite, representar uma ameaça à segurança do requerente.

Percebe-se, portanto, que, na maioria das vezes, o Poder Judiciário ignora que a política de assistência farmacêutica é um meio de garantia do direito a saúde e não só do direito ao medicamento. Ignora também o fato de que muitas prescrições e muitos relatórios médicos estão sendo feitos de forma inadequada, sem respeitar as orientações e normas sanitárias.

Com efeito, a utilização, em algumas sentenças, do argumento de que o Estado tem obrigação de fornecer o medicamento independentemente do que é previsto nos protocolos da rede pública de saúde demonstra o desconhecimento, por parte de alguns juízes, das políticas de saúde vigentes. Cabe destacar, ainda nesse estudo sobre o tratamento para a diabetes, que o recurso ao Judiciário não decorreu de um problema gerencial da Sesab, em relação à falta dos medicamentos. No entanto, o fato da dispensação das insulinas análogas acontecer somente na capital mostra que é necessário melhorar a logística e descentralizar a dispensação desses medicamentos.

Vale também acrescentar que o fato das insulinas análogas não fazerem parte das listas oficiais do SUS não significa que essas listas estejam desatualizadas como, às vezes, argumentam os autores das ações. Nesse caso, as insulinas não constam das relações oficiais, pois não foram recomendadas pela Conitec para incorporação pelo SUS. É preciso ainda registrar que se trata de solicitações de medicamentos de marca, no caso das insulinas análogas, para as quais existem equivalentes já incorporados ao SUS, no caso, as insulinas NPH e regular. Assim, os achados empíricos analisados nesse estudo mostram que as pessoas recorrem ao Poder Judiciário porque os prescritores que as orientam creem que as insulinas análogas são melhores do que a insulina humana regular e a NPH. Por serem medicamentos de alto custo, que não são dispensados pelo sistema público usualmente, os 
pacientes alegam não terem condições financeiras de arcar com os custos desses medicamentos.

Por fim, o terceiro estudo realizado, A judicialização da assistência médica suplementar: um estudo de caso em Pernambuco (ABADE, 2015), deu origem a dois artigos. O primeiro deles, intitulado "Características gerais das sentenças judiciais relativas à assistência médica suplementar proferidas no Tribunal de Justiça de Pernambuco em 2012 e 2013” (ABADE, 2015), identificou que:

a. das 326 ações judiciais estudadas, a maior parte é de autoria individual (95,71\%);

b. as operadoras mais acionadas judicialmente são as de medicina de grupo $(55,52 \%)$ e as empresas de autogestão (26,69\%);

c. os planos antigos estão presentes em $16 \%$ das ações;

d. a principal questão das ações judiciais é a negação de cobertura $(55,8 \%)$;

e. entre os bens e serviços mais citados estão: os medicamentos, as próteses e outros materiais, as cirurgias e os serviços de homecare;

f. em $91 \%$ das ações, a decisão foi favorável aos clientes.

Esses resultados permitem, por um lado, perceber as diferenças regionais no que diz respeito à assistência médica suplementar. Entre elas, vale destacar, em Pernambuco, a grande proporção de empresas de autogestão citadas nas ações, com valores bem superiores à proporção de ações impetradas nos tribunais do Sudeste que citam empresas de autogestão. Outra diferença importante é a aparição, com destaque, das coberturas psiquiátricas como fonte de litígio na assistência médica suplementar.

Por outrolado, deixam ver que dois nós críticos da judicialização da assistência médica suplementar ocorrem tanto em Pernambuco quanto no Rio de Janeiro ou em São Paulo: a coletivização dos planos privados e persistência dos planos não regulados pela Lei n. ${ }^{\circ}$ 9656/98 (por terem sido contratados antes da promulgação da lei). 
Com efeito, quanto às características dos planos e seguros privados de saúde, dois aspectos são importantes para o estudo da judicialização: o tipo de contratação do plano - coletivo ou individual e data da contratação do plano - antes ou depois da Lei n. ${ }^{0}$ 9656/98 -, uma vez que os planos coletivos e aqueles contratados em data anterior à da lei ainda carecem de legislação específica capaz de dirimir os conflitos.

Nesse estudo, é possível observar que os planos coletivos estão presentes em $41,72 \%$ das ações. Os anteriores à lei somam 15,95\%. Nesse cenário, a ocorrência desses nós críticos é resultado da omissão do Estado, no processo de regulação da saúde suplementar. Essa omissão mantém-se como verdadeira leira para conflitos entre clientes e operadoras, sendo do Judiciário a colheita final. Não restam dúvidas que a redução de conflitos na assistência médica suplementar presume a superação dessas duas barreiras.

Quanto à cobertura, principal fonte de litígio, é preciso destacar que se refere, principalmente, a bens e serviços de alto custo, em torno dos quais os interesses de restabelecimento da saúde disputam espaço com os interesses do mercado, dos profissionais e das operadoras. Isso tudo resulta numa complexa teia que precisa ser elucidada, a fim de evitar o uso indevido dos tribunais para a garantia do lucro, em detrimento da saúde da população. Por fim, esse estudo permite afirmar que o perfil das ações judiciais encontrado à luz da segmentação do sistema de saúde brasileiro, do aumento progressivo da cobertura de planos e seguros privados de saúde estimulada pelas políticas governamentais e das fragilidades da regulação, desenham uma tendência de acirramento da litigiosidade.

O segundo artigo fruto dessa dissertação, "Fundamentação das sentenças judiciais relativas à assistência médica suplementar proferidas no Tribunal da Justiça de Pernambuco em 2012 e 2013" (ABADE, 2015), mostra, nas 326 ações judiciais analisadas, que o Código de Defesa do Consumidor (CDC) foi a legislação mais utilizada (45,5\%), possuindo mais do que o dobro de citações da Lei n. ${ }^{\circ}$ 9656/98 (19\%) que regulamenta os planos e seguros privados de 
saúde. As súmulas emitidas pelos tribunais estaduais e pelo Superior Tribunal de Justiça vêm ganhando espaço e já ocupam a segunda posição (20\%). A Constituição Federal de 1988 foi destacada em um número pouco expressivo de litígios (2,6\%). A Lei Orgânica da Saúde não apareceu nas ações analisadas, enquanto que as publicações da ANS estiveram presentes em apenas $10 \%$ das ações, sendo o rol de procedimentos a norma mais citada. Foi possível concluir, a partir do estudo, que o Poder Judiciário, ao dirimir os conflitos entre os clientes e as operadoras de planos e seguros privados de saúde, assumiu o CDC como a legislação prioritária. Ainda que com grande capacidade resolutiva, o uso preponderante do CDC põe a tônica da argumentação na lógica do abuso da relação de consumo, o que demonstra que o conflituoso mosaico estrutural entre o público e privado no sistema de saúde brasileiro não tem sido problematizado nos tribunais.

A análise sobre o uso da regulação demonstra que, ao mesmo tempo em que a ANS se consolidou como o legítimo lócus regulatório, sua atuação é incipiente, limitada a temas específicos, como cobertura e reajustes. Mesmo quando citadas, suas normas não são determinantes das tomadas de decisão. Por sua vez, as falhas da regulação têm oportunizado o aumento do uso das súmulas e de leis específicas, como o Estatuto do Idoso, que legislam, especialmente, nas lacunas da regulação. Vale acrescentar que as questões ligadas ao SUS pouco aparecem na fundamentação das ações. O ressarcimento está completamente ausente e reforça uma compreensão sobre sistema de saúde brasileiro, segundo a qual os sub-sistemas público e privado são independentes.

\section{Considerações finais}

Em tese, o Poder Judiciário pode contribuir para a implantação no Brasil de um sistema de saúde capaz de oferecer um cuidado integral, reduzir iniquidades sociais e superar o modelo biomédico e mercantilista hegemônico. Para tanto, todavia, seria necessário que os princípios construídos no seio da Reforma Sanitária e consagrados 
na Constituição Federal chegassem até o conhecimento dos tribunais e passassem a fundamentar as sentenças que, assim, seriam capazes de influenciar o comportamento de autores e réus de ações judiciais para que ficassem atentos à importância de um sistema de saúde universal para a promoção da justiça social.

Na prática, no entanto, o Poder Judiciário está envolto nas tensões da disputa política que se desenvolve entre os dois projetos de sistemas de saúde que permeiam a sociedade brasileira: se aquele definido na Constituição, que se propõe a ser único e orientado para o atendimento das necessidades de saúde e para a promoção da igualdade, ou se outro, baseado na segmentação da oferta de serviços, de acordo com a capacidade de pagamento das famílias e das empresas.

É justamente para enriquecer o debate e, assim, informar a decisão que a sociedade vier a tomar nessa disputa que as pesquisas científicas sobre a judicialização à saúde são realizadas, produzindo conhecimento que aprofunde a compreensão do fenômeno na sua totalidade, através da análise de suas diversas dimensões éticas, políticas, econômicas, médicas e sociais.

Vale acrescentar que o conhecimento produzido por tais pesquisas pode também subsidiar a formulação e a implantação de políticas de saúde específicas que ajudem a enfrentar os problemas evidenciados pela judicialização - como as falhas da gestão - ou os problemas provocados pela judicialização - como gastos desnecessários ou iníquos.

Os membros do OAPS, responsáveis pelo eixo de acompanhamento das decisões judiciais relativas à saúde, esperam contribuir, com suas pesquisas, para enriquecer o debate científico e político. Além disso, com base nos resultados das pesquisas já realizadas, identificam lacunas no conhecimento sobre o fenômeno que indicam as perspectivas de novos estudos.

Em primeiro lugar, é necessária uma maior compreensão do perfil dos autores das ações judiciais, tendo em vista que a definição desses perfis poderá demonstrar como a judicialização tem modificado o acesso aos serviços de saúde, especialmente, no âmbito do SUS. 
Uma questão correlata se refere à caracterização dos vários atores envolvidos ou interessados no processo da judicializacão da saúde. Tanto os estudos realizados no âmbito do OAPS quanto vários outros já citados (BORGES; UGÁ, 2010; CHIEFFI; BARATA, 2010; DINIZ;MEDEIROS; SCHWARTZ, 2012) identificam a participação de operadores do direito, empresas produtoras ou distribuidoras de bens e insumos para os serviços de saúde, profissionais de saúde, gestores, usuários ou organizações nãogovernamentais na teia da judicialização. Nenhum, contudo, chega a explicitar e discutir as relações e os conflitos de interesses que estabelecem entre si.

Uma terceira questão que deve ser melhor estudada, já sinalizada por alguns estudos (BAPTISTA; MACHADO, 2009; GOMES et al., 2009; HUNT, 2008; PANDOLFO, DELDUQUE, AMARAL, 2012) é a relação entre o campo do direito e o campo da saúde. A ampliação da presença do Poder Judiciário na resolução de conflitos que abarcam as necessidades de saúde, os direitos instituídos e as instituições públicas e privadas que atuam na saúde evidenciou as diferenças entre a racionalidade sanitária e a racionalidade jurídica que, muitas vezes, coloca gestores, usuários, técnicos e magistrados num verdadeiro campo de batalha. O desafio de encontrar uma forma de diálogo entre essas duas racionalidades não é exclusivo do Brasil, mas se faz agudo nos países com pretensos sistemas de saúde universais, nos quais o direito coletivo e direito individual seguem em permanente disputa.

Além de problemas e objetos ainda não analisados, existem os desafios teóricos-metodológicos a superar. Em especial, é preciso discutir quais as melhores formas de se avaliar os impactos da judicialização sobre o sistema de saúde. Apesar da iniciativa pioneira e bastante útil do Manual de Indicadores de Avaliação e Monitoramento das Demandas Judiciais de Medicamentos (PEPE, 2011), ainda não foram apresentadas propostas sistematizadas que abarquem o impacto da judicialização em todas as suas dimensões. Que marco(s) teóri$\mathrm{co}(\mathrm{s})$ podem enriquecer a perspectiva da saúde coletiva na abordagem do fenômeno da judicialização? Quais os métodos mais adequados? 
Enfim, reconhecida a importância do estudo das ações judiciais em seus aspectos políticos, sociais, éticos, jurídicos e sanitários, no aprimoramento das políticas de saúde em curso, avançar nas lacunas empíricas e teórico-metodológicas aqui citadas é um desafio que se impõe para todo o campo da saúde coletiva e que o OAPS se propõe a ajudar a enfrentar.

\section{Referências}

ABADE, E. A. A Judicialização da Assistência Médica Suplementar: um estudo de caso em Pernambuco. 2015. 85 f. Dissertação (Mestrado em Saúde Coletiva) - Instituto de Saúde Coletiva, Universidade Federal da Bahia, Salvador, 2015.

AGÊNCIA NACIONAL DE SAÚDE SUPLEMENTAR. Caderno de informação da saúde suplementar: beneficiários, operadoras e planos. Rio de Janeiro, 2014. Disponível em: <http://www.ans.gov.br/materiaispara-pesquisas/perfil-do-setor/dados-e-indicadores-do-setor $>$. Acesso em: 6 mar. 2014.

BAHIA. Secretaria da Saúde do Estado da Bahia. Centro de Diabetes e Endocrinologia da Bahia. Informe Cedeba, Salvador, ano 4, n. 12, set./out. 2012. Disponível em: <http://www.saude.ba.gov.br/cedeba/informe. pdf $>$. Acesso em: 6 out.2015.

BARDIN, L. Análise de conteúdo. Lisboa: Edições 70:LDA, 1977.

BAPTISTA, T. W. de F.; MACHADO, C. V.; LIMA, L. D.

de.Responsabilidade do Estado e direito à saúde no Brasil: um balanço da atuação dos Poderes. Ciência Saúde Coletiva, Rio de Janeiro, v. 14 n. 3, p. 829-839, Jun. 2009.

BORGE, D. C. L, UGÁ, M. A. D. As ações individuais para o fornecimento de medicamentos no âmbito do SUS: características dos conflitos e limites para a atuação judicial. Revista Direito Sanitário, São Paulo, v. 21, n. 3, p. 438-47, 2009.

BORGES, D. C. L.; UGÁ, M. A. D. Conflitos e impasses da judicialização na obtenção de medicamentos: as decisões de 1a instância nas ações 
individuais contra o Estado do Rio de Janeiro, Brasil, em 2005. Caderno de Saúde Pública, Rio de Janeiro, v. 26, n.1, p. 59-69, jan. 2010.

BRASIL. Amplia produção de medicamentos biológicos. Protec, Rio de janeiro, jun. 2013. Disponível em: <http://site.protec.org.br/farmacose-medicamentos/29185/brasil-amplia-producao-de-medicamentosbiológicos $>$. Acesso em: 15 jul. de 2013.

BRASIL. Ministério da Saúde. Ministro da Saúde apresenta Parcerias de Desenvolvimento Produtivo para empresários. Portal da saúde. Brasília, DF, 2014. Disponível em: <http://www.brasil.gov.br/saude/2014/09/ ministro-da-saude-apresenta-parcerias-de-desenvolvimento-produtivopara-empresarios $>$. Acesso em: 20 de maio de 2015.

CHIEFFI, A. L.; BARATA, R.B. Judicialização da política pública de assistência farmacêutica e eqüidade. Caderno Saúde Pública, Rio de Janeiro, v. 25, n. 8, p. 1839-1849, 2009.

CHIEFFI, A.L, BARATA, R. B. Ações judiciais: estratégica da indústria farmacêutica para introdução de novos medicamentos. Revista de Saúde Pública, São Paulo, v. 44, n. 3, p. 421-429,2010.

CONSELHO NACIONAL DE JUSTIÇA (Brasil). Brasil tem mais de 240 mil processos na área de Saúde. Brasília, DF, 2011. Disponível em: <http://www.cnj.jus.br/noticias/cnj/56636-brasil-tem-mais-de-240-milprocessos-na-area-de-saude>. Acesso em: 23 out. 2015.

COOPER, H.M.; HEDGES, L.V. Research synsthesis as a scientific process. In: COOPER, H.M.; HEDGES, L. V. The handbook of research synthesis and meta-analysis. $2^{\text {nd }}$. New York: The Russel Sage Fundation, 2009. p. 3-16.

D’ESPINDULA, T. C. de A. S. Judicialização da medicina no acesso a medicamentos: reflexões bioéticas. Revista Bioética, Brasília, DF, v. 21, n. 3, p. 438-447. dez. 2013.

DINIZ, D.; MEDEIROS, M.; SCHWARTZ,I.D.D. Consequências da judicialização das políticas de saúde: custos de medicamentos para as mucopolissacaridoses. Caderno Saúde Pública, Rio de Janeiro, v. 28, n. 3, p. 479-489, mar. 2012. 
DRESCH, R. L. Federalismo solidário: a responsabilidade dos estes federativos na área da saúde. In: SANTOS, L.; TERRAZAS, F. (Org.). Judicialização da saúde no Brasil. Campinas: Saberes, 2014. Cap. 1.

GOMES, D. F. et al. Judicialização da saúde e a audiência pública convocada pelo Supremo Tribunal Federal em 2009: o que mudou de lá para cá? Saúde em debate, Rio de Janeiro. v. 38 n. 100, p. 139-156, mar. 2014.

GUIMARÃES, R.et al. Não há saúde sem pesquisa: avanços no Brasil de 2003 a 2010. Revista Baiana de Saúde Pública, Salvador, v. 36, n. 1, p. 55-65, 2012.

HUNT, P.; KHOSLA, R. The human rights to medicines.Sur. Revista Internacional de Direitos Humanos. São Paulo, v. 5, n. 8, p. 101-121, jun. 2008.

LISBOA, E.S. Acesso ao tratamento da diabetes na Bahia: por que se recorre ao judiciário? 2015. 78 f. Dissertação (Mestradoem Saúde Coletiva) - Instituto de Saúde Coletiva, Universidade Federal da Bahia, Salvador, 2015.

LOPES, L.C. et al. Uso racional de medicamentos antineoplásicos e ações judiciais no Estado de São Paulo. Revista Saúde Pública, Rio de Janeiro, v. 44, n. 4, p. 620-628, 2010.

MACHADO, F. R. S.; DAIN, S. Direito e saúde: contribuições para o estudo da judicialização. In: ASENSI, F. D.; PINHEIRO, R. (Org.). Direito sanitário. Rio de Janeiro: Ed. Elsevier, 2012. Cap. 26. p. 463-489.

MARQUES, S. B.; DALLARI, S. G.. Garantia do direito social à assistência farmacêutica no Estado de São Paulo. Revista de Saúde Pública,São Paulo, v. 41 n. 1, p. 101-107, 2007.

MESSEDER, A. M.; OSORIO-DE-CASTRO, C. G. S.; LUIZA, V. L. Mandados judiciais como ferramenta para garantia do acesso a medicamentos no setor público: a experiência do Estado do Rio de Janeiro, Brasil. Cadernos de Saúde Pública, Rio de Janeiro, v. 21, n. 2, p. 525-534, 2005.

PANDOLFO, M.; DELDUQUE, M. C.; AMARAL, R.G. Aspectos jurídicos e sanitários condicionantes para o uso da via judicial no acesso 
aos medicamentos no Brasil. Revista Salud Pública, Rio de janeiro, v. 14, n. 2, p. 340-349, 2012.

PEPE, V. L. E. (Org.). Manual indicadores de avaliação e monitoramento das demandas judiciais de medicamentos. Rio de Janeiro: Fundação Oswaldo Cruz, Escola Nacional de Saúde Pública Sergio Arouca, 2011. RYAN, G.W.; BERNARD, H. R. Data management and analysis methods. In: DENZIN, N. K.; LINCONL, Y.S. Handbook of qualitative research. Califórnia: Sage Publications, 2000. p. 769-802.

REIS, C.; PIERONI, J. P.; SOUZA, J. O. B. Biotecnologia para saúde no Brasil-BNDES. Setorial, Rio de Janeiro, n. 32, p. 193-230, 2010.

SANTOS, B. S. Os tribunais nas sociedades contemporâneas: o caso português. Porto: Ed. Afrontamento, 1996. (Coleção Saber Imaginar o Social, n. 8).

SANTOS, L.; TERRAZAS, F. Judicialização da saúde no Brasil. Campinas: Saberes, 2014.

SHEFFER, M. Coberturas assistenciais negadas pelos planos e seguros de saúde em ações julgadas pelo tribunal de justiça do estado de São Paulo. Revista Direito Sanitário, São Paulo, v. 14, n. 1, p. 122-132, 2013. SCHEFFER, M.; SALAZAR, A. L.; GROU, K. B. O remédio viaJustiça: um estudo sobre o acesso a novos medicamentos e exames em HIV/Aids no Brasil por meio de ações judiciais. Brasília, DF: Ministério da Saúde, 2005.

TOBAR, F.; YALOUR, M. R. Como fazer teses em saúde pública: conselhos e ideias para formular projetos e redigir teses e informes de pesquisa. Rio de Janeiro: Ed. Fiocruz, 2001.

TORRES, I. D. C. Judicialização do acesso a medicamentos no Brasil: uma revisão sistemática. 2013. 86 f. Dissertação (Mestrado em Saúde Coletiva) - Instituto de Saúde Coletiva, Universidade Federal da Bahia, Salvador, 2013.

TORRES, I. D. C. Análise das ações judiciais de medicamentos na Secretaria de Saúde do Estado da Bahia - 2002 a 2008. 2010. 67 f. Trabalho 
de Concurso de Curso (Especialização) - Faculdade de Farmácia, Universidade Federal da Bahia, Salvador, 2010.

VIEIRA, F. S. Ações judiciais e direito à saúde: reflexão sobre a observância aos princípios do SUS. Revista de Saúde Pública, São Paulo, p. 365-369, v. 42 n. 2, p. 365-369, abr. 2008.

VIEIRA F. S.; ZUCCHI, P. Demandas judiciais e assistência terapêutica no Sistema Único de Saúde. Revista da Associação Médica Brasileira,São Paulo, v. 55, n. 6, p. 672-683, 2009. 